\title{
Anthropometry of Body Circumferences of Yorubas of Nigeria
} Okoh $\mathrm{PD}^{1 *}$, Didia BC ${ }^{2}$

\author{
${ }^{1}$ Department of Surgery, Faculty of Clinical Sciences, University of Port Harcourt Teaching Hospital, Port Harcourt, Nigeria \\ ${ }^{2}$ Department of Anatomy, Faculty of Basic Medical Sciences, College of Health Science, University of Port Harcourt, Port Harcourt, Nigeria
}

The aim of the research was to study the circumferential anthropometric body characteristics of adult male Yorubas of Nigeria. The study design was a non-experimental, cross-sectional design. It utilised a total number of four hundred (400) subjects whose ages ranged between 21 to 40 years with BMI of 18.50 to <30.00. Minimum sample size was determined using the Taro Yamane's formula. Circumferential body anthropometric measurements and BMI were taken using stadiometer, digital calipers, calibrated flexible meter tape and weighting scale. Statistical analysis was done using statistical package for the social science (SPSS version 25.0) and Microsoft Excel 2019. Continuous variables were presented as mean $\pm \mathrm{SD}$; minimum and maximum. Age was categorized into two groups $(21-30$ and 31 - 40) years while Body Mass Index (BMI) was also categorized into two; normal weight $(18.5-24.9$ designated $\leq$ $25.0)$ and slightly overweight $(25.0-30.7$ designated $\geq 25.0)$. Independent sample t-test was therefore carried out to determine significant difference in the measured anthropometric parameters according to age. The confidence interval was set at $95 \%$, therefore $\mathrm{p}<0.05$ was considered significant. Results were presented in tables. Impact of age and variations in BMI were also observed in the studied anthropometric variables. Racial variation was observed when compared to other racial populations the anthropometric values could find use in medicine and forensic science.

Keywords: Circumferential, body, gross, anthropometry, Yoruba.

Copyright @ 2020: This is an open-access article distributed under the terms of the Creative Commons Attribution license which permits unrestricted use, distribution, and reproduction in any medium for non-commercial use (NonCommercial, or CC-BY-NC) provided the original author and source are credited.

\section{INTRODUCTION}

Anthropology encompasses the study of the physical variation of man, and relies on external measurements of the human body proportions and skeleton, for description, analysis and classification of fossils and human populations. Although human anatomy describes the structure of the body as observed in most people and has traditional value in surgery, there exists a wide range of ethnic and racial variations in the physical appearance and body proportions of different populations [1]. Anthropometric studies are therefore undertaken along the lines of these variations. Studies have shown variation with respect to sex [2-5], changes due to age [6] and variations between different populations $[3,7,8,9,10,11,12,13]$. Anthropometric measurements have been adopted as methods in clinical and public health works, as they are applicable to large samples and can provide national estimates and data for the analysis of secular changes [14]. It therefore becomes necessary to generate data that would describe the circumferential anthropometric body features of this negroid population.

\section{Materials ANd Methods Research Design}

The research design was a non-experimental, cross-sectional design which catalogued values of the circumferential anthropometric body features of adult male Yoruba of Nigeria using anthropometric standards.

\section{Sample Size and Sampling Technique}

Subjects were randomly selected from amongst adult male Yorubas resident in Akure, Idanre, Akoko and Okitipupa in Ondo State. A total number of four hundred (400) adult males were used for the study. The minimum sample size was determined using the Taro Yamane's formula which states that:

$n=\frac{\mathrm{N}}{1+\mathrm{N}(\mathrm{e})^{2}}$ Where $\mathrm{n}=$ minimum sample size, $\mathrm{N}=$ population size, $\mathrm{e}=$ error $\operatorname{margin}=0.05$

Only adult males between the ages of 21 and 40 years with BMI of 18.50 to $<30.00$ were included in this study. From our study, it was observed that individuals whose BMI fell within the range 
categorized as overweight looked apparently healthy. It was ascertained that recruited subjects had both parents and four grand parents from the same ethnic group.

\section{METHOD}

The study employed circumferential body anthropometric measurements. Measurements were carried out by fifteen trained personnel. The following circumferential measurements were taken using appropriate landmarks: Midarm Circumference, Chest Circumference, Abdominal (Waist) Circumference, Hip Circumference and Midthigh Circumference. Measurements were taken with the aid of stadiometer, digital calipers, calibrated flexible meter tape, meter rule and weighing scale.

\section{IDENTIFICATION OF LANDMARKS}

Mid-arm circumference (also mid upper arm circumference)

This is the point between the acromion process of scapula and olecranon process of ulna.

\section{Chest circumference}

This is the region corresponding to the nipples - the xiphoid process.

\section{Waist circumference}

This is the region, corresponding to the superior iliac crest and then crosses the line to indicate the mid-axillary line of the body.

\section{Hip circumference}

This is the area corresponding to the inguinal region, the area relating to the groin (the area between the abdomen and thigh).

\section{Thigh circumference}

This is the mid-point between the greater tubercle of femur and the lateral epicondyle of the femur.

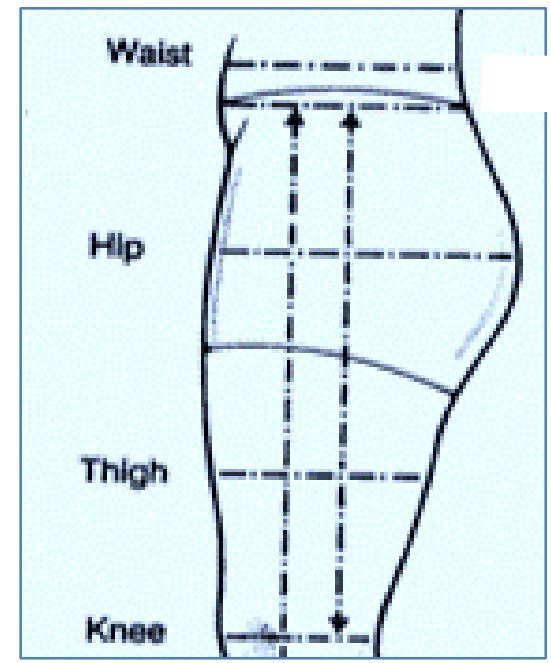

Fig-1: Lower body circumferential measurements: waist, hip, thigh and knee circumferences

\section{Procedure}

The following procedures describe methods for the anthropometric measurements for each of the parameters:

\section{Upper arm circumference}

The subject stands with the elbow relaxed so that the right arm hangs freely to the side.

The measuring tape is placed around the midupper arm at the point perpendicular to the long axis of the upper arm (at the medial part of the mid-arm).

The tape is held so the zero ends is held below the measuring value.

The tape rests on the skin surface but not pulled tight enough to compress the skin.

The upper arm circumference is recorded to the nearest $0.1 \mathrm{~cm}$.

\section{Chest circumference}

The subject stays in a standing position with both hands spread side by side. The measuring tape is placed horizontally at the medial part of the chest (the region corresponding to the nipples - the xiphoid process).

The measuring tape is then placed at the right side and passed round through the back and back to the starting point.

The chest circumference is then carried out with minimal respiration to the nearest $0.1 \mathrm{~cm}$ and recorded.

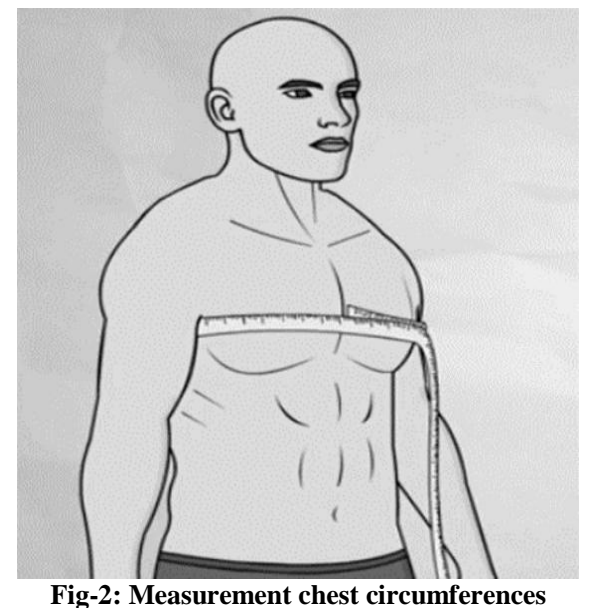

\section{Waist circumference}

The subject stays in a standing position.

The measuring tape is placed horizontally at the waist region, corresponding to the superior iliac crest and then crosses the line to indicate the mid axillary line of the body. 
The measuring tape is placed at the right side around the trunk in a horizontal plane at this level marked on the right side of the trunk.

The measuring tape is then carried around the subject to make sure the tape is parallel and ensure the tape is snug but not compressing the skin.

The measurement is then carried out at minimal respiration to the nearest $0.1 \mathrm{~cm}$ and recorded.

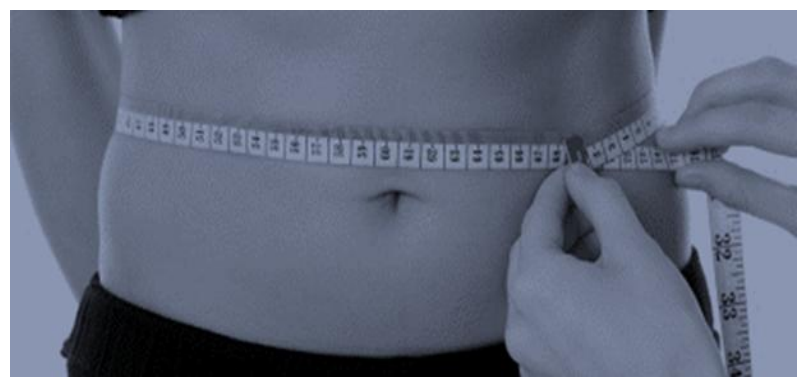

Fig-3: Waist circumference measurement

\section{Hip circumference}

The Subject stands erect with feet together and weight evenly distributed on both feet.

The measuring tape is placed at the inguinal region, the area relating to the groin (the area between the abdomen and thigh).

The sides of the tape are then adjusted and the front side is checked to ensure that the plane of the tape is horizontal.

The zero end of the tape is then held under the measurement value.

The tape is held snug but not tight.

Measurement is then taken from the right side and recorded.

Table-1: Descriptive statistics of the circumferential body measurements of the Yoruba

\begin{tabular}{|c|c|c|c|}
\hline Circumferential body measurements & \multicolumn{3}{|c|}{$[\mathbf{N}=\mathbf{4 0 0}]$} \\
\cline { 2 - 4 } & Mean \pm SD & Min & Max \\
\hline MAC & $27.10 \pm 2.29$ & 2.52 & 36.50 \\
\hline CC & $92.47 \pm 5.99$ & 9.34 & 119.50 \\
\hline WC & $96.44 \pm 3.27$ & 87.41 & 100.62 \\
\hline HC & $96.14 \pm 3.89$ & 86.50 & 104.13 \\
\hline MTC & $55.42 \pm 3.43$ & 48.20 & 61.50 \\
\hline
\end{tabular}

$\boldsymbol{M A C}=$ Mid arm circumference, $\boldsymbol{C C}=$ Chest circumference, $\boldsymbol{W C}=$ Waist circumference, $\boldsymbol{H C}=$ Hip circumference, $\boldsymbol{M T C}=$ Midthigh circumference, $\boldsymbol{S D}=$ Standard deviation, Min $=$ Minimum, Max $=$ Maximum

\section{Mid-thigh circumference}

The subject stands with the right leg just in front of the left leg and the weight shifted back to the left leg.

A table may be used to maintain the subject's balance. The measuring tape is placed around the medial part of the mid-thigh, the tape is positioned perpendicular to the long axis of the thigh with the zero end of the tape held below the measuring value.

The tape rests firmly on the skin without compressing the skin and ensured the tape is placed correctly. The thigh circumference is then carried out to the nearest $0.1 \mathrm{~cm}$ and recorded.

\section{STATISTICAL ANALYSIS}

Statistical analysis was done using statistical package for the social science (SPSS version 25.0) and Microsoft Excel 2019. Continuous variables were presented as mean $\pm \mathrm{SD}$; minimum and maximum. Age was categorized into two groups $(21-30$ and $31-40)$ years while Body Mass Index (BMI) was also categorized into two; normal weight $(18.5-24.9)$ and slightly overweight $(25.0-30.0)$. Independent sample ttest was therefore carried out to determine significant difference in the measured anthropometric parameters according to age and BMI. The confidence interval was set at $95 \%$, therefore $\mathrm{p}<0.05$ was considered significant.

\section{RESULTS}

Results are presented in tables $1-3$. Only WC showed a statistically significant difference $(\rho=0.00)$ on comparison between the age groups using the independent sample t-test. No significant difference was observed in the other circumferential parameters (table 2). 
Table-2: Descriptive statistics of the measured circumferential body measurements according to age in Yoruba Subjects

\begin{tabular}{|c|c|c|c|c|c|c|c|c|}
\hline \multirow{2}{*}{$\begin{array}{c}\text { Circumferential } \\
\text { Body } \\
\text { Measurements }\end{array}$} & \multirow{2}{*}{$\begin{array}{c}\text { Age } \\
\text { group }\end{array}$} & \multirow[t]{2}{*}{$\mathbf{N}$} & \multirow[t]{2}{*}{ Mean } & \multirow[t]{2}{*}{ SD } & \multicolumn{4}{|c|}{$t$-test } \\
\hline & & & & & Df & $t$-value & $p$-value & Inference \\
\hline \multirow[t]{2}{*}{ MAC } & $21-30$ & 327 & 27.15 & 1.99 & \multirow[t]{2}{*}{398.00} & \multirow[t]{2}{*}{0.76} & \multirow[t]{2}{*}{0.45} & \multirow[t]{2}{*}{ Not Significant } \\
\hline & $31-40$ & 73 & 26.92 & 3.34 & & & & \\
\hline \multirow[t]{2}{*}{$\mathrm{CC}$} & $21-30$ & 327 & 91.32 & 6.23 & \multirow[t]{2}{*}{398.00} & \multirow[t]{2}{*}{-1.03} & \multirow[t]{2}{*}{0.30} & \multirow[t]{2}{*}{ Not Significant } \\
\hline & $31-40$ & 73 & 92.12 & 4.72 & & & & \\
\hline \multirow[t]{2}{*}{$\mathrm{WC}$} & $21-30$ & 327 & 94.11 & 2.95 & \multirow[t]{2}{*}{88.76} & \multirow[t]{2}{*}{-3.43} & \multirow[t]{2}{*}{0.00} & \multirow[t]{2}{*}{ Significant } \\
\hline & $31-40$ & 73 & 95.88 & 4.16 & & & & \\
\hline \multirow[t]{2}{*}{$\mathrm{HC}$} & $21-30$ & 327 & 95.12 & 3.95 & \multirow[t]{2}{*}{398.00} & \multirow[t]{2}{*}{-0.23} & \multirow[t]{2}{*}{0.82} & \multirow[t]{2}{*}{ Not Significant } \\
\hline & $31-40$ & 73 & 95.23 & 3.67 & & & & \\
\hline \multirow[t]{2}{*}{ MTC } & $21-30$ & 327 & 53.34 & 3.36 & \multirow[t]{2}{*}{398.00} & \multirow[t]{2}{*}{-1.04} & \multirow[t]{2}{*}{0.30} & \multirow[t]{2}{*}{ Not Significan } \\
\hline & $31-40$ & 73 & 53.80 & 3.76 & & & & \\
\hline
\end{tabular}

$\boldsymbol{M A C}=$ Mid arm circumference, $\boldsymbol{C C}=$ Chest circumference, $\boldsymbol{W C}=$ Waist circumference, $\boldsymbol{H C}=$ Hip circumference, $\boldsymbol{M T C}=$ Midthigh circumference, $\boldsymbol{S D}=$ Standard deviation

Table-3: Descriptive statistics of the measured circumferential body measurements according to BMI in Yoruba

\begin{tabular}{|c|c|c|c|c|c|c|c|c|}
\hline \multicolumn{9}{|c|}{ Subjects } \\
\hline \multirow{2}{*}{$\begin{array}{l}\text { Circumferential } \\
\text { Body } \\
\text { Measurements }\end{array}$} & \multirow[t]{2}{*}{ BMI } & \multirow[t]{2}{*}{$\mathbf{N}$} & \multirow[t]{2}{*}{ Mean } & \multirow[t]{2}{*}{ SD } & \multicolumn{4}{|c|}{$t$-test } \\
\hline & & & & & Df & $t$-value & $p$-value & Inference \\
\hline \multirow[t]{2}{*}{ MAC } & Normal weight & 308 & 27.14 & 2.08 & \multirow[t]{2}{*}{398.00} & \multirow[t]{2}{*}{0.57} & \multirow[t]{2}{*}{0.57} & \multirow[t]{2}{*}{ Not Significant } \\
\hline & Slightly overweight & 92 & 26.98 & 2.90 & & & & \\
\hline \multirow[t]{2}{*}{$\mathrm{CC}$} & Normal weight & 308 & 91.33 & 6.20 & \multirow[t]{2}{*}{398.00} & \multirow[t]{2}{*}{-0.81} & \multirow[t]{2}{*}{0.42} & \multirow[t]{2}{*}{ Not Significant } \\
\hline & Slightly overweight & 92 & 91.91 & 5.21 & & & & \\
\hline \multirow[t]{2}{*}{$\mathrm{WC}$} & Normal weight & 308 & 94.43 & 3.35 & \multirow[t]{2}{*}{398.00} & \multirow[t]{2}{*}{-0.04} & \multirow[t]{2}{*}{0.97} & \multirow[t]{2}{*}{ Not Significant } \\
\hline & Slightly overweight & 92 & 94.45 & 3.01 & & & & \\
\hline \multirow[t]{2}{*}{$\mathrm{HC}$} & Normal weight & 308 & 95.22 & 3.88 & \multirow[t]{2}{*}{398.00} & \multirow[t]{2}{*}{0.76} & \multirow[t]{2}{*}{0.45} & \multirow[t]{2}{*}{ Not Significant } \\
\hline & Slightly overweight & 92 & 94.87 & 3.95 & & & & \\
\hline \multirow[t]{2}{*}{ MTC } & Normal weight & 308 & 53.57 & 3.54 & \multirow[t]{2}{*}{171.98} & \multirow[t]{2}{*}{1.68} & \multirow[t]{2}{*}{0.09} & \multirow[t]{2}{*}{ Not Significant } \\
\hline & Slightly overweight & 92 & 52.94 & 3.03 & & & & \\
\hline
\end{tabular}

$\boldsymbol{M A C}=$ Mid arm circumference, $\boldsymbol{C C}=$ Chest circumference, $\boldsymbol{W C}=$ Waist circumference, $\boldsymbol{H C}=$ Hip circumference, $\boldsymbol{M T C}=$ Midthigh circumference, $\boldsymbol{S D}=$ Standard deviation

Table 3 shows descriptive statistics of the circumferential body measurements according to BMI in Yoruba subjects. No statistically significant difference $(\rho>0.05)$ was observed.

\section{DISCUSSION}

Various human populations possess characteristics that distinguish them from the others. Different groups of people are distinguished by anthropologists on the basis of common origin; on whether they were living or had lived in certain defined regions and had possessed different characteristic features in their appearance. Variations are observed in groups who live in different geographical areas within the single species [15]. Variations in different races and groups could be due to factors such as biological, environmental, nutritional, geographical, social factors among others.
This study provides a catalogue of the circumferential body anthropometry of the Yoruba of Nigeria. Circumferential body measurements together with body mass index (BMI) have been implicated in various studies ranging from evaluation of nutritional status [16, 17], risk of cardiovascular disease [18] and birth weight [19]. Mid arm circumference has been reported in Iran. The mid-arm circumference of the Yoruba was lower than those reported in Iran; $280 \pm 31 \mathrm{~mm} \quad(28.0 \mathrm{~cm}), \quad 282 \pm 33 \mathrm{~mm} \quad(28.2 \mathrm{~cm})$, $285 \pm 29 \mathrm{~mm} \quad(28.5 \mathrm{~cm}), \quad 283 \pm 26 \mathrm{~mm} \quad(28.3 \mathrm{~cm})$, $282 \pm 30 \mathrm{~mm}(28.2 \mathrm{~cm})$ and $284 \pm 27 \mathrm{~mm}(28.4 \mathrm{~cm})$ for age groups $25-29,30-34,35-39,40-44,45-49$ and $50-55$ respectively[20]. With respect to age [6], only waist circumference showed a statistically significant difference $(\rho=0.00)$ on comparison between the age groups using the independent sample t-test. No significant difference was observed in the other circumferential parameters (table 2). Among the BMI groups, no statistically significant difference $(\rho>0.05)$ was observed. 


\section{CONCLUSION}

Dearth of literature on most circumferential parameters made it difficult to compare those parameters. Values obtained from this study describe what could be considered normal for this negroid race. This study could find use in the manufacture of gross anatomical models using negroid standards. It can also serve as a reference for future use and also find use in medical practice and forensics.

\section{Consent}

It is not applicable.

\section{Ethical approval}

As per international standard or university standard, written approval of Ethics committee has been collected and preserved by the author(s).

\section{Competing interests}

interests exist.

Authors have declared that no competing

\section{REFERENCES}

1. Moore KL, Agur AMR. Essential Clinical Anatomy 2nd Edition. Lippincott Williams and Wilkins. 2002; 3 - 4 .

2. Pazos JAT, Galdames ICS, Lopez MC, Matamala DAZ. Sexual Dimorphism in the Nose Morphotype in Adult Chilean. Internet Journal of Morphology, 2008;26 (3):537-542.

3. Njemirovskij V, Radovic Z, Komar D, Lazic B, Kuna T. Distribution of Craniofacial Variables in South Dalmatian and Middle Croatian Populations. Collection of Anthropology, 2000;24 (1): 49-56.

4. Oladipo GS, Dike UE, Hart JS, Amadi MA, Jumbo NF. A Study on Some Oro-Facial Variables of Adults of Bonny Ethnic Group in Nigeria. International Journal of Current Microbiolology and Applied Sciences, 2014;3(7): 926-937.

5. Shah M, Verma IC, Mahadevan S, Puri RK. Facial anthropometry in Newborns in Pondicherry. Indian Journal of Paediatrics, 1991;25:259-63.

6. Lee HJ, Park SJ. Comparison of Korean and Japanese Head and Face Anthropometric Characteristics. Human Biology, 2008;80(3): 313330.

7. Ngeow WC, Aljunid ST. Craniofacial Anthropometric Norms of Malays. Singapore Medical Journal, 2009;50 (5):525

8. Porter JP. The Average American Male Face - An Anthropometric Analysis. Archives of Facial Plasticic Surgury, 2004;6:78-81.

9. Golalipur MJ, Haidari K, Jahanshahi M, Farahani RM. The Shapes of Head and Face in Normal Male Newborns in South-East of Caspian Sea (IranGorgan). Journal of the Anatomical Society of India, 2003;52(1):28-31
10. Porter JP, Olson KL. Anthropometric Facial Analysis of the African American woman. Archives of Facial Plastic Surgery, 2001;3:191-197

11. Baral P, Lobo SW, Menezes RG, Kanchan T, Krishan K, Bhattacharya S, Hiremath SS. An anthropometric study of facial height among four endogamous communities in the Sunsari district of Nepal. Singapore Medical Journal, 2010;51(3):212

12. Du L, Zhuang Z, Guan H, Xing J, Tang X, Wang L, Wang Z, Wang H, Liu Y, Su W, Benson S, Gallagher S, Viscusi D, Chen W. Head-and-Face Anthropometric Survey of Chinese Workers. Annals of Occupational Hygiene, 2008;52(8):773782.

13. Grbe D, Pezerovic-Panijan R, Kalaya MN, Gorsic I, Cavcik A, Zura N, Berberovic, B. Craniofacial Characteristics of Croatian and Syrian Populations. Collection of Antropology, 2007;31(4):1121-1125.

14. Brown N, Scurr J. The Need for a Standardized Anthropometric Protocol for Objective Assessment of Pre - and Postoperative Breast Surgery. Gland Surgery. 2012; 1:3. www.glandsurgery.org/index

15. Bhasin MK. Racial, Ethnic, Religious and Linguistic Elements in Indian Population. Indian Anthropology, Gurgaon 122 002, Haryana, India: 2007

16. Ibegbu AO, Tosin DE, Hamman WO, Umana, UE, Musa, SA. Nutritional evaluation using different anthropometric variables in Nigerian school children. Journal of experimental and clinical anatomy (JECA). 2013; 12 (2): 42 - 49.

17. Dale NM, Myatt M, Prudhon C, Briend A. Using mid-upper arm circumference to end treatment of severe acute malnutrition leads to higher weight gains in the most malnourished chidren. PLoS One. 2013;8(2):55404.

18. Cheng X, Tran NTT, Blizzard CL, Luong KN, Truong NLV, Tran BQ, Otahal P, Nelson M, Magnussen C, Gall S, Bui TV, Srikanth V, Au TB, Ha ST, Phung HN, Tran MH, Callisaya M. The importance of waist circumference and body mass index in cross-sectional relationships with risk of cardiovascular disease in Vietnam. PLoS One. 2018; 13(5): 0198202. https:// doi: 10.1371/journal.pone.0198202

19. Thi HN, Khanh DKT, Thu HLT, Thomas EG, Lee KJ, Russell FM. Foot Length, Chest Circumference, and Mid Upper Arm Circumference Are Good Predictors of Low Birth Weight and Prematurity in Ethnic Minority Newborns in Vietnam: A Hospital-Based Observational Study. PLoS ONE 2015; 10 (11): e0142420.

20. Ayatollahi SMT. A Systematic Review of Reference Values for Mid Upper Arm Circumference (MUAC) in Southern Iran. Journal of Obesity and Weight loss Therapy. 2012; 2:119. 